\title{
STUDY ON THE SOCIAL SIGNIFICANCE OF RECREATIONAL SPORT
}

\author{
Urichianu Bogdan Andrei ${ }^{1}$, Urichianu Adrian ${ }^{2}$, Dima Marius ${ }^{3}$, Urichianu Toma-Sanda ${ }^{4}$ \\ ${ }^{1.2}$ Titu Maiorescu University, Bucharest, Romania \\ ${ }^{3,4}$ Romanian American University, Bucharest, Romania, email:sandavtoma@yahoo.com
}

\section{SUMMARY}

The acceleration of contemporary world events, global social, political and economic transformations that have changed traditions and ideologies into new forms adopted by young generations have also brought new content, methods and skills to the field of physical education and sport that have reformed the system and are able to respond to solving unknowns that have pushed to another stage the practice of sports activities.

The development of information technology has attracted the lack of interest of young people for movement through forms of practice, known as sometimes unattractive.

The purpose of this study is to argue the rethinking of the composition of physical education programs, the discovery of solid evidence based on the reasons for practicing physical sports, the presentation of models to follow and the adaptation of basic structures to human evolution.

Assumption. In this study we tried to find out what are the elements that could motivate students to practice physical sports.

The results we reached after the study confirmed that more and more students prefer to spend their free time with activities other than sports and those who still prefer movement choose activities that offer fun, play and recreation.

Keywords: recreational sports, physical education, leisure, health.

\section{INTRODUCTION.}

Performing physical exercises can be put into practice in the physical education lesson, as an educational instructional process or by practicing independent sports or leisure activities that can be organized by the school as a sports ensemble, with family, friends, or playing sports.

Time management and the educational program often do not allow young people to practice movement in their free time, they limit themselves to participating in physical education lessons. Free time is mostly occupied by fun or more attractive, comfortable activities, which often means gadgets and other electronic toys.

Practicing physical exercises by participating in recreational sports physical activities is in the attention of society and especially of the family since the birth of the child and then in all stages of life.

The importance that has movement is found in biological development of the human being and is the natural basis of society and personality development. 
In the 21 st century, society faces global challenges, such as sedentary lifestyles, obesity, unemployment and conflicts of all kinds. These risk factors are at the heart of the goal of sustainable development, on quality education, which advocates for lifelong learning opportunities and innovative content (Strategy 2014-2021, UNESCO).

During childhood, the tasks of physical education are to ensure the necessary conditions to allow the timely maturation of internal organs, body functions and the optimal development of personality. With the evolution of society, physical demands are influenced by the appearance of negative factors, for a normal physical development and even for health. Physical education in interaction with the other branches of education will include in its educational-formative content new problems, such as those related to hygiene education, sex education, correction of physical deficiencies.

In fact, we live in a world with predispositions to sedentary lifestyles and nervous overload, in which maintaining health and developing motor skills has become a major issue of global educational interest.

Physical exercise and the sport has always been a social activity with real biological character, both contributing to improved qualities motive of man and thereby increase the level and quality of life. From time immemorial, systematic, organized physical exercises have influenced the harmonious growth and development of the body in childhood and adolescence, have contributed to maintaining health and the formation of positive behaviors necessary for man in adulthood.

The practice of some sports is done voluntarily, based on the establishment of objectives that aim to obtain performance or for recreation.

The fundamental characteristics of physical education are the following (Cârstea, G., 2000):

- is physiological by the nature of the exercises;

- is pedagogical by method;

- is biological by effects;

- is social through organization.

According to Prodea, C., (2014) physical education always involves practical and applied activities. This is a fundamental type of motor activity that is carried out on the basis of laws, norms, methodologies, etc., in order to obtain general and special competencies. Physical education comes in two forms: physical education lesson and independently practiced sports activities.

The independent activity of practicing physical exercises should be part of the daily activities of each of us, to be a permanent means that is practiced efficiently and pleasantly in our free time. 
The Sports and Fitness Industry Association (SFIA) has conducted an online survey in 39 US states for people over the age of 6 on their favorite sports and other favorite physical activities. A ranking of the first 10 activities grouped by age was prepared and a number of participants participated 287,138,000 subjects.

Swimming is the most popular activity for almost all age groups. Apart from swimming, most options are for outdoor activities. Children aged 6 to 12 are particularly interested in excursions, young people aged 18-24 are more interested in running / jogging. The bicycle is also a more attractive means for adults aged 25-54.

With the development of physical education courses, we proceeded to apply a questionnaire to first and second year students of the Faculty of Law at "Titu Maiorescu" University, on their availability regarding free time and how much they could allocate from this time for physical exercise.

Assumption. We proposed that by analyzing the answers to some questions addressed to students to find out their preferences regarding the ways of practicing sports activities in their free time.

The aim of this study is to optimize the effects of students' physical development and to help encourage as many of them as possible to spend their free time actively.

The research methods used are: pedagogical observation, study of documents and specialized bibliography, questionnaire, tabulation of results, graphic method.

\section{Research objectives}

The main objective of the research is to discover the preferences, among students, of those physical activities of a sporting nature that can be practiced in their free time.

Another objective of the research is the analysis of physical activity trends, based on the options registered by students, because they prove receptivity, responsibility for their own training, they are motivated by their interests, motivations, inclinations, aspirations.

\section{Materials and methods.}

For data collection we used the survey (based on questionnaire) and the observation method.

For data processing and analysis we used the statistical-mathematical method, the formation of tables and the graphical method.

\section{Subjects.}

This study was applied to a number of 240 students in years I and II of the university, during the academic year 2018-2019. 
Table no.1 Students participating in the answers to the questionnaire according to the year of study

\begin{tabular}{|c|c|c|c|}
\hline \multicolumn{2}{|c|}{ Years I } & \multicolumn{2}{|c|}{ Years II } \\
\hline girls & boys & girls & boys \\
\hline 71 & 49 & 64 & 56 \\
\hline \multicolumn{2}{|c|}{ Total $=120$} & \multicolumn{2}{|c|}{ Total $=120$} \\
\hline
\end{tabular}

Fig. no.1 Graphic representation of the number of subjects, by years of studies

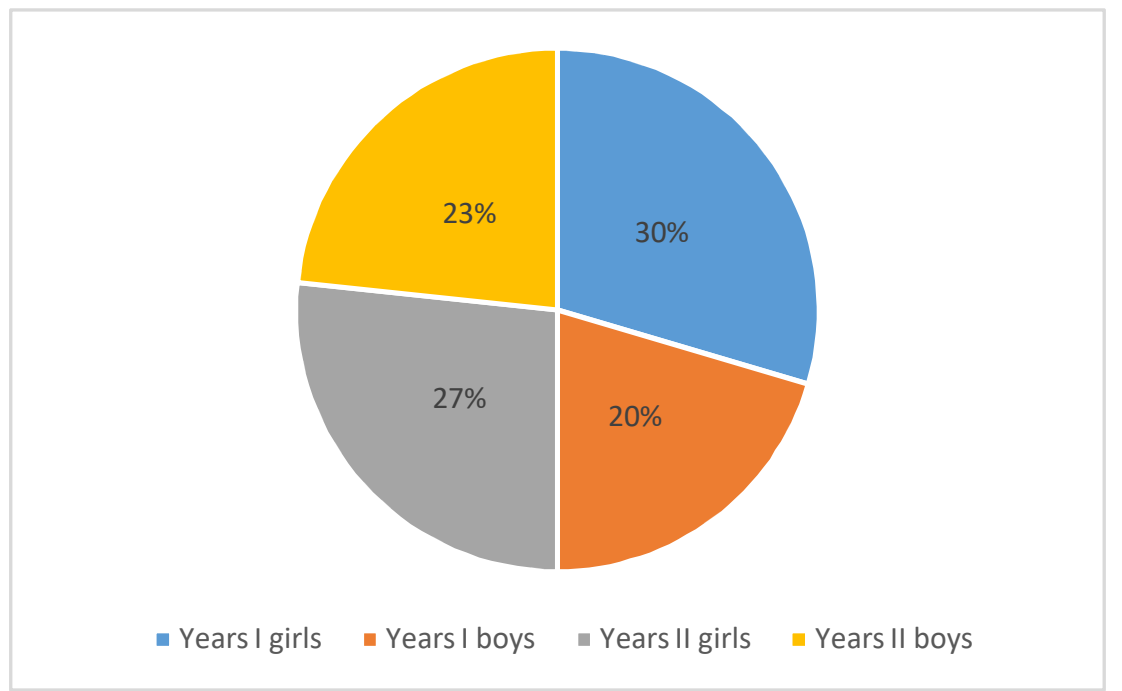

Table no. 2 Students participating in the answers to the questionnaire according to gender

\begin{tabular}{|c|c|}
\hline Total girls & Total boys \\
\hline 135 & 105 \\
\hline \multicolumn{2}{|c|}{ Total subjects $=140$} \\
\hline
\end{tabular}

Fig. no.2 Graphic representation of the number of subjects, depending on gender

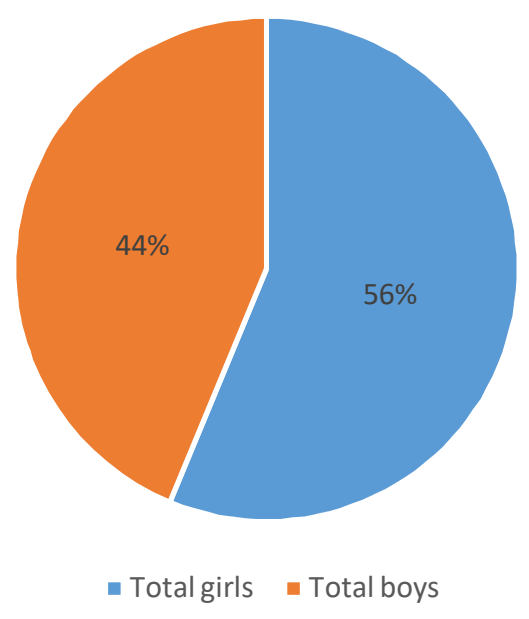




\section{Results}

Of the 12 questions used in the questionnaire, I illustrate the following three questions, which are the most representative:

In question no. 1. How much free time do you have, on average, a day to exercise?

Note: a) do not have, b) less than an hour, c) 1 - 2 hours, d) 2 - 3 hours, e) 3 - 4 hours

f) over 4 hours

Table no.3 Answers to question no. 1

\begin{tabular}{|c|c|c|c|c|}
\hline \multirow{2}{*}{ Answers } & \multicolumn{2}{|c|}{ Year I } & \multicolumn{2}{c|}{ Year II } \\
\cline { 2 - 5 } & girls & boys & girls & boys \\
\hline Answer 1a & 3 & 3 & 2 & 2 \\
\hline Answer 1b & 6 & 6 & 2.3 & 20 \\
\hline Answer 1c & 15 & 17 & 21 & 19 \\
\hline Answer 1d & 25 & 26 & 11 & 9 \\
\hline Answer 1e & 17 & 13 & 6 & 5 \\
\hline Answer 1f & 5 & 4 & 1 & 1 \\
\hline Total & 71 & 69 & 64 & 56 \\
\hline
\end{tabular}

Fig. no. 3 Graphic representation of the answers to question no.

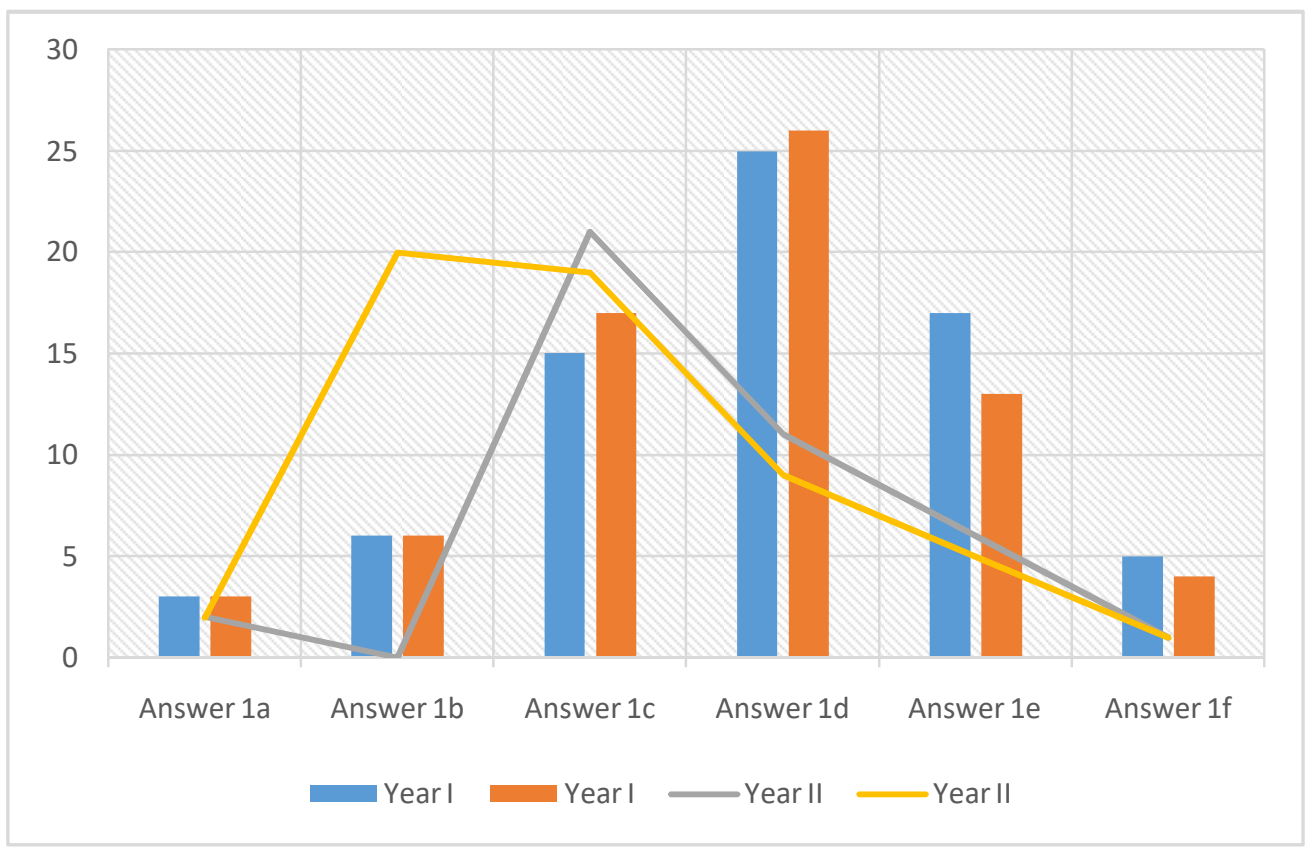

Note from the students' answers that their free time is concentrated in greater numbers around the answers that correspond to the period of less than 1 hour for the second year girls and boys and the first year students allocate approximately 2 hours for the practice of sports activities . Most well it initiates students do not have free time for sports or limited to less than 1 hours.

Question no. 2. In what form would you like to practice your physical exercises? 
a) gymnastics; b) basic gymnastics c) jogging, running; d) tourism, excursions, hikes, walks; e) movement games, fun; f) aerobic gymnastics, dance; g) sports games; h) swimming; i) table tennis, tennis, badminton; j) martial arts; k) fitness; 1) sports; m) chess

Table no. 4 Answers to question no. 2

\begin{tabular}{|c|c|c|c|c|}
\hline \multirow{2}{*}{ Answers } & \multicolumn{2}{|c|}{ Year I } & \multicolumn{2}{|c|}{ Year II } \\
\hline & girls & boys & girls & boys \\
\hline Answer 2a & 2 & 4 & 3 & 3 \\
\hline Answer 2b & 2 & 3 & 5 & 4 \\
\hline Answer 2c & 10 & 9 & 12 & 9 \\
\hline Answer 2d & 6 & 9 & 6 & 6 \\
\hline Answer $2 \mathrm{e}$ & 14 & 11 & 8 & 7 \\
\hline Answer 2f & 10 & 14 & 10 & 7 \\
\hline Answer $2 \mathrm{~g}$ & 10 & 7 & 7 & 6 \\
\hline Answer $2 \mathrm{~h}$ & 1 & 2 & 3 & 3 \\
\hline Answer $2 \mathrm{i}$ & 6 & 8 & 4 & 4 \\
\hline Answer $2 \mathrm{j}$ & 3 & 1 & 2 & 0 \\
\hline Answer 2k & 2 & 0 & 1 & 3 \\
\hline Answer 21 & 4 & 1 & 2 & 4 \\
\hline Answer $2 \mathrm{~m}$ & 1 & 0 & 1 & 0 \\
\hline total & 71 & 69 & 64 & 56 \\
\hline
\end{tabular}

Fig. no.4 Graphic representation of the answers to question no. 2

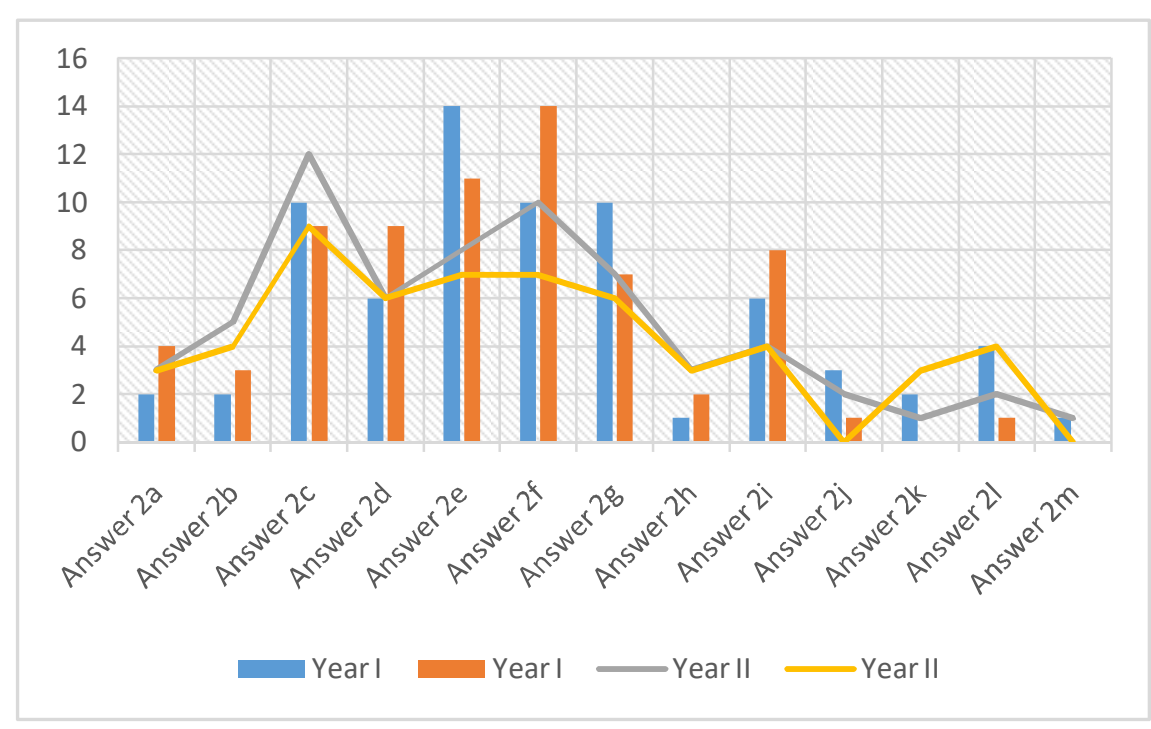

From the students' answers to question no. 2 it results that most people prefer light sports activities represented by jogging, running, tourism, excursions, hiking, walking, movement games, fun, aerobic gymnastics, dance. Fewer students practice fitness and performance sports. Question no. 3. How important are exercise to you? 
a) very important ; b) important ; c) I should pay more attention to the sport; d) not at all important

Table. No.5 Answers to question no. 3

\begin{tabular}{|c|l|l|l|l|}
\hline \multirow{2}{*}{ Answers } & \multicolumn{2}{|c|}{ Year I } & \multicolumn{2}{c|}{ Year II } \\
\cline { 2 - 5 } & \multicolumn{1}{|c|}{ girls } & \multicolumn{1}{c|}{ boys } & girls & boys \\
\hline Answer 3a & 32 & 28 & 2.3 & 22 \\
\hline Answer 3b & 20 & 26 & 27 & 20 \\
\hline Answer 3c & 16 & 12 & 13 & 12 \\
\hline Answer 3d & 3 & 3 & 1 & 2 \\
\hline Total & 71 & 69 & 64 & 56 \\
\hline
\end{tabular}

Fig. no.5. Graphic representation of the answers to question no. 3

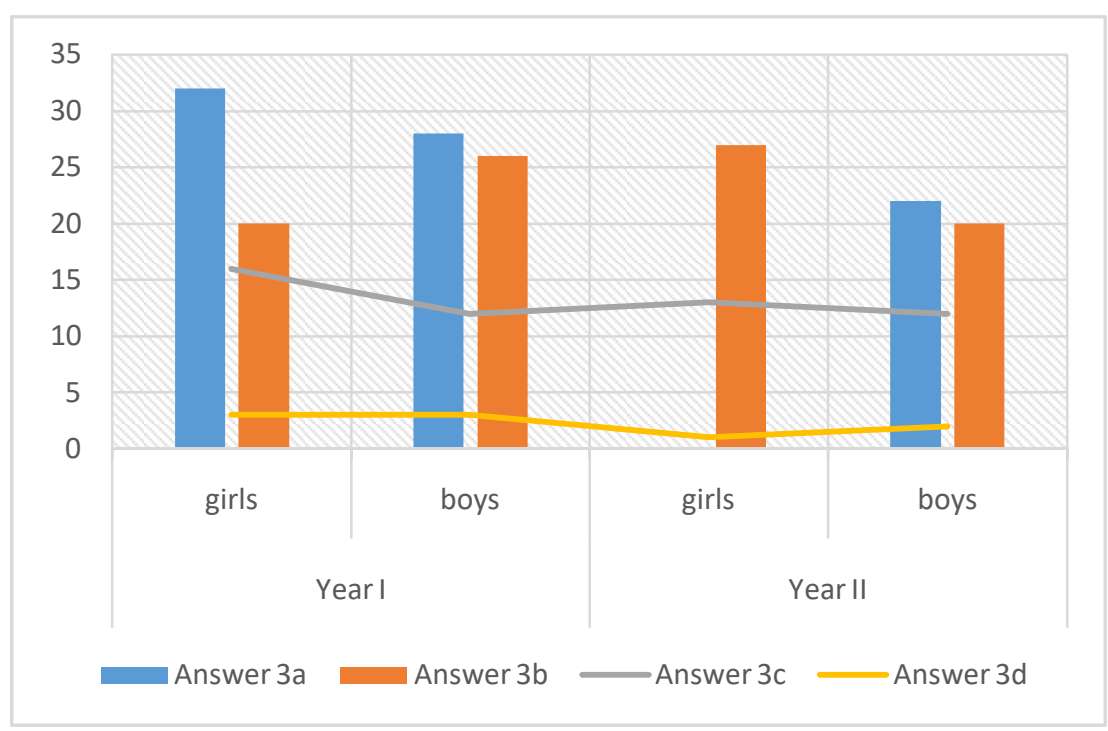

From the answers to question no. 3 it results that the students agree with the importance of practicing physical exercises and this determines them to try to make time for this type of activities.

\section{Interpretation of results.}

From the answers of the subjects we would notice that the students agree and have a variety of physical activities with sports character and know the consequences of the sedentary lifestyle represented by the lack of movement.

There are some significant differences regarding the occupation of free time with physical activities determined by the sex of the subjects, namely the girls were constantly in second place, they prefer walking.

Regarding the structure of free time and the place occupied by the practice of physical exercises in the leisure budget, they are influenced by how busy the subjects are. 
At the same time, the material conditions available to the students, the geographical position, the local tradition, etc. are very important.

Most of the answers received confirm the personal beliefs regarding the practice of physical education, the recognition of favorable influences on health and intellectual performance, which are widely accepted.

Other conditions on which the practice of sports activities in their free time depends are represented by the material situation, the state of health, the favorable climate.

The investigated students mostly prefer the following types of sports activities: fitness, aerobic gymnastics, jogging, tennis, swimming, volleyball, karate, cycling, etc.

Girls generally motivate not to participate in sports activities due to lack of free time, allocating too much space for other sedentary activities.

Subjects who have difficulty practicing sports agree that most often the reasons are: lack of will, material conditions, fatigue after classes, work, financial problems, lack of sports education, poor health.

\section{CONCLUSIONS}

Following the study, we appreciate that the practice of physical exercises in the future is part of the concerns, if not daily, at least weekly, of students, this type of activity being a logical and absolutely necessary continuation of the physical education activity.

The physical effort made in the physical education lessons is completed with recreational, disconnecting, diversified activities with an adequate and successful content, able to attract continuous practice throughout life.

At the same time, where possible, universities can motivate students to participate in leisure sports by providing them with their material bases, terrain, halls, trails, swimming pools to offer a greater variety of sports.

In support of the recommendations coming from the educational, social, family environment, it is necessary a continuous information and stimulating actions from the mass media for the knowledge, understanding and acceptance by different categories of the population of the need to exercise in the future in various forms.

We believe that the media, the family, the university need to put more emphasis on creating the environment available for students in terms of the importance of independent exercise in their free time. 


\section{REFERENCES}

1. Bota, A., Physical exercises for an active life, Motor activities for free time, Cartea Universitară Publishing House, Bucharest, 2006,

2. Cârstea, G., Theory and methodology of physical education and sports, Universul Publishing House, Bucharest, 2000 ,

3. Chivar, GM, Free time and sports activities for students from "Babeş-Bolyai" University of Cluj-Napoca, PhD thesis, Babes Bolyai University, Cluj Napoca, 2016,

4. Cucoş, C., Pedagogy, Polirom Publishing House, Iaşi, 1996,

5. Dragnea, A., Bota A., Theory of motor activities. Bucharest Didactic and Pedagogical Publishing House, 1999,

6. Epuran, M., Dragnea, A., et al., Methodology required for citation of bodily activities, Vol. I; Vol. II, IEFS, 1994,

7. Liao, T., F., Beckman, J., Marzolph, E. et al; The social definition of time for university students, in Time \& Society 2013 http://tas.sagepub.com

8. Medium-Term Strategy 2014-2021, United Nations Educational Scientific and Cultural Organization http://unesdoc.unesco.org/images/0022/002278/227860e.pdf

9. Prodea, C., Psychomotor / physical education; methodology of their teaching in preschool and primary education, Faculty of Psychology and Educational Sciences Specialization Pedagogy of Primary and Preschool Education, Course, Cluj Napoca 2014. 